\title{
Polyploidy in Orchid Breeding, Advances and Perspectives
}

\author{
Pablo Bolaños-Villegas ${ }^{1,2,3 *}$, Fure-Chyi Chen ${ }^{4}$ \\ 1 Fabio Baudrit Agricultural Research Station, University of Costa Rica, La Garita, Alajuela 20101 and Costa \\ Rica \\ 2 Lankester Botanical Garden, University of Costa Rica, Dulce Nombre, Cartago 30109, Costa Rica \\ 3 School of Agronomy, Department of Food and Agricultural Sciences, University of Costa Rica, Rodrigo \\ Facio Campus, Montes de Oca, San Jose 11503, Costa Rica \\ 4 General Research Service Center, National Pingtung University of Science and Technology, Taiwan \\ *Corresponding author:E-mail: pablo.bolanosvillegas@ucr.ac.cr
}

\begin{abstract}
The orchid market is a dynamic horticultural business in which novelty and beauty command high prices. The development of miniature to large and showy flowers, in addition to fragrance, is mainly of interest. Overall organ size might be modified by doubling the chromosome number, which can be accomplished by careful study of meiotic chromosome disjunction in hybrids or species. Meiosis is the process in which diploid (2n) pollen mother cells recombine their DNA sequences and then undergo two rounds of division to give rise to four haploid (n) cells called sporads. Thus, by interfering in chromosome segregation, one can induce the development of diploid recombinant sporads called dyads. These dyads may be used for breeding polyploid progenies with enhanced fertility and large flower size. This review gives an overview of developments in orchid breeding placed in the large context of ploidy breeding in higher plants to facilitate innovation.
\end{abstract}

Keywords: orchid breeding; polyploidy; meiosis; fertility; organ size

\section{Introduction}

Orchids, including Phalaenopsis, also called the moth orchid, are among the most popular ornamental potted plants currently traded around the world ${ }^{1}$. Other famous genera traded are Cymbidium, the Chinese 'lan' orchid 2; Dendrobium 3; Paphiopedilum, the famous lady slippers ${ }^{4}$; Oncidium, the dancing-lady orchids ${ }^{5}$; and Cattleya ${ }^{6}$, among many others.

To remain competitive, new orchid cultivars must be developed continuously to meet the market demands ${ }^{5}$. Usually, both wild species and commercial cultivars are chosen as parent plants in breeding programs that rely on interspecific hybridization and selection of progenies ${ }^{1}$ because sexual reproduction may increase heterosis and diversity of traits ${ }^{2}$, including flower longevity ${ }^{6}$. Nonetheless, high infertility is often the result of breeding these advanced orchid hybrids ${ }^{7}$. The reported causes are many, varying from untimely tapetal degeneration in Oncidesa ${ }^{5}$ to premature chromatid separation and formation of lagging chromosomes during metaphase I in Aranda ${ }^{8}$. Misplaced bivalents with no clear position along the spindle, also called pseudo-bivalents, have also been reported in Vanda semi-terete diploid hybrids ${ }^{9}$. Traditionally fertility can be restored in these orchid hybrids by doubling the number of chromosomes with antimitotic agents such as colchicine and oryzalin during tissue culture ${ }^{7}$; the result is called allotetraploid ${ }^{10}$. The process induces disomic pairing of homologous chromosomes during meiosis I and the creation of balanced gametes ${ }^{7}$.

Polyploid orchids, including autopolyploids (which arise from a single species) have desirable traits such as large flowers with great substance, round conformation and intense coloration, and thicker stems and leaves ${ }^{7}$. In Cymbidium, newly synthesized sexual allopolyploids such as 'Yutao' show increased width and thickness of sepal, petal, and lips, and flowers are rounder and produce more fragrance, therefore with increased commercial value ${ }^{2}$. Sexual polyploids are bred from naturally produced unreduced gametes, 
and these plants are considered better than those obtained from somatic polyploidization because of the resulting genetic diversity and heterosis ${ }^{2}$.

Evolutionarily speaking, polyploid organisms are often more resilient to extreme environments and cataclysms because of their increased genetic variation and the buffering effect of their duplicated genes ${ }^{11,12}$. For instance, whole genome duplications (WGDs) may have contributed to gene diversification and fine-tuning of orchid ovule initiation and closure of the stigmatic cavity, as in the case of the DROOPING LEAF/CRABS CLAW $(D L / C R C)$-like genes in Phalaenopsis equestris and Dendrobium catenatum ${ }^{13}$. Also, in the genome of $P$. equestris, a large WGD event was associated with the Cretaceous-Paleogene extinction about 66 million years ago. This WGD is believed to have been followed by intense radiation that enabled the Orchidaceae to become the second largest angiosperm plant family with its remarkable diversity in flower morphology ${ }^{14}$.

In nature, orchid autotetraploids of Gymnadenia conopsea exhibit high pollination and fruiting success ${ }^{15}$, possibly because of changes in flower scent, changes in pollinaria morphology, larger flowers, and low inbreeding depression ${ }^{15}$. Thus, a higher reproductive fitness of tetraploids than diploids may enable them to become more common ${ }^{15}$. In fact, genome duplication events are assumed to be beneficial for orchid breeders in search of new morpho-types and improvements in size, substance, and form ${ }^{16}$.

This review gives an overview of meiotic mechanisms and breeding techniques that allow for polyploidization of plant gametes to highlight opportunities for molecular breeding in orchids for the accelerated creation of a new generation of elite hybrids.

\section{Understanding alloploidy}

Allopolyploids are usually created by hybridizing distantly related species $($ allo $=$ different); thus, the resulting individual may have divergent genomes combined within its own chromosome complement ${ }^{17}$. Merging genomes from different species provides genome variation and novel opportunities to diversify, with the added advantage that gene redundancy may mask recessive deleterious alleles by dominant ones ${ }^{17}$. Also, the expression of genes required for chromatid cohesion and meiosis may be enhanced, as observed in the Arabidopsis suecica allopolyploid ${ }^{18}$. The frequency of multivalents has been used as a cytological factor to distinguish auto- and allopolyploids. For instance, a high frequency of multivalent pairing at metaphase I may point to homology between chromosome sets and thus autopolyploidy ${ }^{19}$. However, in contrast, a high formation of bivalents at diakinesis may result from pairing between non-homologous (homoeologous) parental chromosome sets, which may indicate allopolyploidy ${ }^{19}$, although this behavior is not absolute ${ }^{19}$. In the actual case of orchid breeding, the development of cultivars with multiple spikes involves crossing species such as Phalaenopsis micholitzii (with multiple short spikes) and Phalaenopsis tetraspis (long spikes) ${ }^{20}$. The resulting hybrid, $P$. Tzu-Chiang Tetralitz, develops up to five spikes ${ }^{20}$. In many cases, tissue culture induces spontaneous polyploidization of hybrids ${ }^{20}$, but selection is laborious, and crosses must be redone often to retain stability of traits in the progenies. Early generations of synthetic allopolyploids show quick and broad reorganization of the merged genomes, including chromosome rearrangements and changes in chromosome number as well as epigenetic modifications, such as transposon activation, chromatin modifications and altered methylation patterning ${ }^{19}$. Indeed, chromosome rearrangements are often observed in meiocytes of presumptive orchid allopolyploids ${ }^{21}$, along with micronuclei in tetrads. These micronuclei are common in human cancer cells and arise from hypomethylation in peri-centromeric DNA, dysfunctional kinetochore assembly, poor organization of the spindle, or uncoordinated expression of anaphase checkpoint genes ${ }^{22}$.

\section{Molecular mechanisms for polyploidization}

Although several reproductive mechanisms may create polyploid plants, most plants are formed by the random production of diploid (2n) gametes ${ }^{23}$. However, despite the huge biological and agricultural significance of forming diploid gametes, the molecular 
mechanisms that lead to the formation are not well understood ${ }^{23}$. Cytologically, 2n gametes possess the somatic chromosome number because of meiotic defects, which leads to a mitosis-like/non-reduced division with dyads ( $2 n)$ formed alongside triads ( $3 n$ ) and normal haploid tetrads (n) ${ }^{24}$, a phenomenon called meiotic nuclear restitution ${ }^{24}$. Most of these $2 n$ gametes result from a few basic processes of nuclear restitution: 1 ) omission of meiosis I (also called first division restitution [FDR]), 2) omission of meiosis II (also called second division restitution [SDR]), 3) defects in spindle organization and 4) incomplete cytokinesis 24,25 .

In eukaryotes, meiotic cell division halves the chromosome number in gametes via a single DNA replication followed by two events of chromosome segregation ${ }^{26}$. During meiosis I, homologous chromosomes should pair and synapse and exchange genetic information via recombination. Then the sites cross over, called chiasmata, form physical links between the two homologs and ensure 1) proper placement of the bivalent in the spindle and 2) proper segregation of homologs during anaphase I 27 . To achieve this, sister kinetochores from each homolog attach to microtubules extruding from the same spindle pole (e.g., monopolar kinetochore attachment), and cohesion is removed at the chromosome arms but not centromeres. Then during meiosis II, chromosome segregation in the two new haploid nuclei proceeds in an equational fashion. Chromatid centromeres are attached bipolarly to the microtubules up to anaphase II, when cohesion is finally removed to ensure that chromatids segregate into four haploid daughter cells ${ }^{27}$.

\section{Synapsis, chromosome segregation and meiotic non-reduction}

Meiotic division and gametophytic ploidy are tightly regulated processes at the molecular level, and many of these regulators have been successfully characterized ${ }^{25}$. For instance, mutations in the Arabidopsis thaliana gene DYAD/SWITCH1 (SWI1; At5g51330) functioning in cohesion regulation ${ }^{28}$ and its maize and rice homologs, both named $A M E I-$ OTIC1 (GRMZM5G883855 and Os03g44760) ${ }^{29}$, lead to the abrogation of synapsis during meiosis I and rather turn it into a mitotic-like cycle ${ }^{30}$. However, in the Arabidopsis mutants parallel-spindle 1 or Jason, disturbed orientation of the spindle leads to a similar effect ${ }^{31}$. These features are often referred to as examples of FDR ${ }^{31}$ and are somewhat common in amphihaploid- and polyhaploid-wide $\mathrm{F}_{1}$ hybrids in which homology is very low and meiotic pairing does not occur ${ }^{26}$. Thus, some researchers consider that this type of meiotic non-reduction is better described as asynaptic- or univalent-dependent ${ }^{26}$.

And what is synapsis? At the early stages of meiosis, homologous chromosomes find each other within the tight confines of the nucleus and then become fully aligned in a process called homologous chromosome pairing ${ }^{32}$. Once chromosome stretches are paired, those same regions will be held together by a scaffold of proteins called the synaptonemal complex (SC). This tight alignment is called synapsis and allows for recombination, in which information is exchanged between the parental homologs and generates crossovers that promote faithful chromosome segregation during meiosis I ${ }^{32}$. Arabidopsis genes that regulate establishment of the cohesion (e.g., the entrapment of DNA) between homologous chromosomes can affect the assembly of synaptonemal complex. Such genes include STRUCTURAL MAINTENANCE OF CHROMOSOMES 5 (SMC5; At5g15920), STRUCTURAL MAINTENANCE OF CHROMOSOMES 6 A/B (SMC6A/B; At5g07660, At5g61460) and PRECOCIOUS DISSOCIATION OF SISTERS 5 (PDS5A/E; At5g47690, At1g77600, At4g31880, At1g80810, and At1g15940). However, whether these mutants show signs of FDR during meiosis is unclear. Another gene that regulates synapsis and cohesion is SYNAPTIC1, also known as RECOMBINATION 8/SYNAPTIC 1 (REC8/SYN1; At5g05490 ${ }^{33}$. This gene has a severe impact on meiotic synapsis by affecting the correct polymerization of the SC 31 , and its absence during meiosis I leads to illegitimate interhomolog recombination and catastrophic chromosome fragmentation ${ }^{31}$. Univalents are also produced owing to failure to synapse, but their chromosomes are extremely tangled, and distinguishing them is difficult ${ }^{34}$. Thus, because the phenotype is so extreme, it might 
be necessary to develop weak alleles to induce a FDR-like phenotype that might be useful for orchid breeding.

For the formation of $2 \mathrm{n}$ gametes through SDR, several Arabidopsis genes have been linked to the omission of meiosis II, including OMISSION OF SECOND DIVISION 1 (OSD1; At3g57860, also known as GIGAS and UVI4-Like), a key negative regulator of the anaphase-promoting complex/cyclosome (APC/C), that may control the turnover of cyclins to elicit the exit from mitosis or meiosis ${ }^{35,36}$. Another gene is the plant A-type cyclin gene CYCA1;2/TARDY ASYNCHRONOUS MEIOSIS (TAM; At1g77390), which is essential for the transition between the first and second meiotic division and whose mutations cause exit from meiosis after prophase ${ }^{35}$. In Arabidopsis, mutants for TAM develop diploid gametes ${ }^{35}$, whereas mutants for OSD1 develop triploid or tetraploid gametes ${ }^{35}$. Combining both mutations leads to the production of tetraploid spores, and by adding mutant alleles for meiotic recombination (spo11-1) and for segregation (rec8/syn1), meiosis is completely abrogated in the tam or osd1 backgrounds. This results in the now legendary Mitosis into Meiosis $(\mathrm{MiMe})$ phenotype ${ }^{35}$ that was introduced in rice to produce apomictic progenies identical to the mother plant ${ }^{37}$. This might be an interesting approach to massreproduce valuable orchid hybrids, perhaps by CRISPR-Cas-mediated transformation, as was done recently in Taiwan with the orchid model species P. equestris ${ }^{38}$.

A third gene that is epistatic to both OSD1 and TAM is SUPPRESSOR WITH MORPHOGENETIC EFFECTS ON GENITALIA7 (SMG7; At5g19400) ${ }^{39}$. This gene may operate as a regulator of the first to second meiotic division transition, probably by downregulating or inducing the degradation of $C D K A ; 1^{39}$. Pollen mother cells in the $s m g 7$ mutants that arrest during anaphase II do not seem to form any pollen, as seen by Alexander Red staining ${ }^{39}$. Perhaps yet-identified alleles of interest may be present in orchids.

\section{Cytokinesis, temperature stress and polyploidy}

Cytokinesis is another key cellular process that may lead to the production of polyploid gametes ${ }^{25}$. In plants, meiotic cytokinesis is timed to occur after chromosome segregation, but the process varies somewhat between dicots and monocots ${ }^{40}$. In dicots such as Arabidopsis, meiotic cell walls are synthesized after the separation of the sister chromatids, which occurs at the final stages of meiosis II, called simultaneous cytokinesis ${ }^{40}$. Nevertheless, in monocots such as rice and maize, meiotic cytokinesis involves the synthesis of a cell wall after each round of chromosome segregation. Hence, a dyad is formed at the end of meiosis I, whereas tetrads are formed after meiosis II ${ }^{40}$. This type is called successive cytokinesis. Mitogen-activated protein kinases (MAPKs) are common signal transduction factors that control meiotic cytokinesis ${ }^{25}$, and they operate in a relay fashion, a signaling cascade, that may involve MAPK kinase kinases, MAPK kinases (MKKs), and MAPKs, which are activated sequentially by phosphorylation at conserved activation sites 41. Of these, the interaction between Arabidopsis NPK1-ACTIVATING KINESIN 2/TETRASPORE (NACK2/TES, At3g43210), NPK1-RELATED PROTEIN KINASE 3 (ANP3, At3g06030), MKK6 (At5g56580), and MAPK4/At4g01370 have been shown to mediate male meiotic cytokinesis ${ }^{40,41}$. In the case of the tes mutants, all tetrads share the same cytoplasm and initiate male gametogenesis together, thus leading to the formation polyploid sperm, as seen by DAPI staining ${ }^{42}$. This situation is presumably due to defects in the assembly of the radial microtubule system (also called the phragmoplast), which leads to severe microtubule accumulation in nuclear surfaces and total failure to establish cytoplasmic domains ${ }^{42}$. Of note, mutants for suppressors of gibberellin signaling, specifically rga-24 and gait6, show similar alterations at telophase II, thus leading to the formation of diploid gametes in Arabidopsis (3.3\%). Spraying with $100 \mu \mathrm{M} \mathrm{GA} 3$ caused the same phenotype (3\%) in the Ler phenotype ${ }^{25}$.

Work in A. thaliana and Brassica napus has shown that heat, cold and drought stress may affect the expression or activity of MAPKs ${ }^{41}$. Remarkably, in Arabidopsis, heat stress (36-38 ${ }^{\circ} \mathrm{C}$ for $24 \mathrm{~h}$ ) caused defects in cytokinesis at metaphase I, namely reduced abundance of microtubule fibers, failure to form a bipolar spindle, formation of multiple mini- 
phragmoplasts at anaphase I, and total failure to form a radial microtubule system at the tetrad stage ${ }^{40}$. Moreover, fluorescent in situ hybridization with a centromere probe suggested that during meiosis I, homologous recombination or crossover formation is impaired, because only univalents are observed ${ }^{40}$.

Cold stress is effective in inducing the formation of $2 \mathrm{n}$ gametes in Arabidopsis ${ }^{30}$. With cold shock treatment of 4 to $5^{\circ} \mathrm{C}$ for up to $40 \mathrm{~min}$ followed by sampling 7 days later, $6 \%$ to $38 \%$ of flowers showed enlarged pollen grains. The sperm nuclei in these pollen grains consistently showed extra centromere foci, as seen by expression of the $p W O X 2: C E N H 3: G F P$ centromeric reporter construct, thus suggesting the formation of diploid, triploid, and tetraploid male spores ${ }^{30}$. Results indicate defects in the formation of cell plates between tetrads at telophase II, which suggests that these are recombinant, SDR-type unreduced gametes ${ }^{30}$. Perhaps this approach could be used in orchid breeding programs as well.

\section{Recombination, heat stress and polyploidy}

The relation between heat stress $\left(36-38^{\circ} \mathrm{C}\right.$ for $\left.24 \mathrm{~h}\right)$ and reduced meiotic recombination has been explored in $A$. thaliana by immunostaining and transcriptional analyses ${ }^{43}$. Apparently, assembly of the synaptonemal complex is disturbed, as seen by changes in the distribution and abundance of the chromosome axis protein ASY1NAPTIC1 (ASY1, At1g67370) and lateral element/transverse filament protein ZYP1A (At1g22260) and by the absence of bivalents at metaphase I. The expression of recombinase RAD51 (At5g20850) is also reduced, which suggests impaired processing of double strand breaks usually implemented by the conserved type-II topoisomerase SPO11 (At3g13170) ${ }^{43}$. Abnormal tetrads were observed, including what appeared to be dyads ${ }^{43}$. Thus, taken together, heat stress appears to be valuable for the formation of unreduced-like gametes, probably nearly FDR-type ones. A potential caveat is that ZYP1A is also involved in the formation of class I interfering crossovers ${ }^{44}$, and in its absence, crossover formation is not prevented but rather promoted, as seen by an increase of up to $50 \%$ in levels of the crossover makers HEI10 and MLH1 ${ }^{45}$.

Heat stress $\left(34^{\circ} \mathrm{C}\right.$ vs $21^{\circ} \mathrm{C}$, for up to 1 week) has been shown to shorten meiosis in Arabidopsis from $21.1 \mathrm{~h}$ at $21^{\circ} \mathrm{C}$ to $18.1 \mathrm{~h}$ at $34^{\circ} \mathrm{C}{ }^{46}$. Ingeniously combining time-lapse analyses of microtubule organization (TagRFP-TUA5), breakage of the nuclear envelope (NEB), localization of CDKA;1-stress granules (CDKA;1-mVenus) and assembly of the SC in chromosomes (ASY1-RFP and ZYP1b-GFP) concluded that during zygotene, ASY1 is unexpectedly depleted and the loading of ZYP1 is aborted abruptly. The abortion is possibly due to activation during pachytene of a newly discovered plant cell-cycle checkpoint controlled by the kinase ATAXIA TELANGIECTASIA MUTATED (ATM; At3g48190) ${ }^{46}$. In these heat-stressed meiocytes, homologs fail to pair properly, and chromosome bridges and fragments are observed, possibly caused by non-homologous recombination ${ }^{46}$. The value of this type of work in the context of orchid breeding is that the expression of these constructs could be attempted by Agrobacterium-mediated transformation in Phalaenopsis, as done in Taiwan ${ }^{38}$ for the analysis of meiosis in response to all types of experimental conditions.

\section{Polyploidization and recombination}

In Phalaenopsis orchids, species and primary $F_{1}$ hybrids are usually diploid, whereas elite varieties are tetraploid ${ }^{47}$; examples are Phalaenopsis Sogo Yukidian 'V3'(see Figures 1A and 1B), Phalaenopsis Tai Lin Red Angel 'V31' and Phalaenopsis Brother Irene 'Feng Fong'. All have $2 n=4 x=76$ chromosomes ${ }^{48}$. Such parental varieties are sexually crossed with other varieties and species to introgress traits such as quick growth, ease of clonal reproduction, fragrance, and resistance to disease ${ }^{48}$. Thus, enhanced sexual recombination might constitute a valuable horticultural asset.

Work in Brassica allotriploids (AAC genome, $2 n=3 x=29$ ) derived from the species Brassica rapa (AA genome, $2 n=2 \mathrm{x}=20$ ) and Brassica napus (AACC genome, $2 n=4 \mathrm{x}=38$ ) 
has shown an increase in crossover formation (1.7 to 3.4 times), possibly corresponding to type I interfering crossovers ${ }^{49}$. This work involved use of 199 single nucleotide polymorphisms (SNPs) evenly distributed across chromosomes and revealed that the increase in recombination is the highest in female plants, at long chromosomes and at pericentromeric regions ${ }^{49}$. This type of work involves the use of $60 \mathrm{~K}$ Illumina Infinium Arrays, and perhaps a similar approach could be attempted in orchids.

Also, the combination of cytogenetics and SNP markers can assist in the identification of regulators for aberrant homoeologous recombination in genotypes that are suspected to be genetically unstable, as in the case of the B. napus double haploid population SGDH ${ }^{50}$. This is useful for orchid breeding because partial homoeology has been suggested to cause meiotic irregularities and defective tetrad formation in orchids such as Aranda 'Christine' C80 ${ }^{8}$, an old interspecific hybrid known for being genetically unstable ${ }^{8}$. Illegitimate recombination between homoeologues may cause aneuploidy because homoeologous bivalents, multivalents and univalents may not segregate correctly at meiosis $\mathrm{I}^{50}$. Also, the uneven exchange can lead to gain or loss of homoeologous segments when chromatids segregate ${ }^{50}$. In Brassica napus SGDH plants, the formation of multivalents seems common, as observed by fluorescent in situ hybridization, and duplications and deletions are widespread, as confirmed by using SNP markers. Most of this variation seems linked to the presence of a region 10.3 to $23.9 \mathrm{Mbp}$ nested within chromosome 9, named BnaA9, which shows a strong change in the expression of orthologues for REPLICATION PROTEIN A 1C (RPA1C; At5g45400) and MMS and UV Sensitive 81 (MUS81; $A t 4 g 30870)^{50}$. The endonuclease MUS81 is an important mediator in the resolution of recombination intermediates such as double Holliday junctions ${ }^{51}$, whereas RPA1C is part of the heterotrimeric RPA complex that mediates activation of DNA damage checkpoints 52.

Thus, although in polyploid hybrids, it might be possible to fingerprint for alleles that might cause genetic instability, breeders might want to look for a long-term solution. Cytologically, in allo-haploid, tissue-cultured Brassica napus cv. Tanto, the reduction in copy number of ARABIDOPSIS MUTS HOMOLOG 4 (MSH4; At4g17380), by just one copy, effectively reduced the frequency of events of homoeologous recombination, possibly constituting an evolutionary mechanism for fine-tuning meiosis ${ }^{53}$. This gene is part of the main crossover pathway, called the ZMM pathway because it involves genes ZIP1, MER3, MSH4, MSH5, SHOC1, HEI10, and PTD. Remarkably, many of them (e.g., MER3, MSH4 and MSH5) show rapid loss of duplicates following evolutionary events of WGD in angiosperms ${ }^{53}$ (Gonzalo et al., 2019). One might envision the use of CRISPR-Cas9 editing to trim the number of MSH4 duplicates in orchid polyploids to stabilize meiosis. In fact, in allopolyploids, the ZMM pathway could be targeted to reduce the number of crossovers to the bare minimum, one per chromosome pair to prevent inter-homoeologue crossover formation ${ }^{53}$.

\section{Post polyploid diploidization in orchids}

In the 1960s in Hawaii, allopolyploid Vanda hybrids showed preferential pairing of chromosomes during meiosis ${ }^{9}$. Then in the 1980s in Malaysia, the diploid species Calanthe veratrifolia showed evidence of asynchronous segregation of subgroups of chromosomes during meiosis, involving multiple spindles, perhaps suggesting a polyploid ancestry or concealed hybridity ${ }^{54}$ (Teoh, 1982). In those days, this behavior was called complement fractionation ${ }^{54}$ (Teoh, 1982). Currently this phenomenon is better known as post-polyploid diploidization (PPD) ${ }^{12}$, and it may have driven the evolution of paleo- and mesopolyploid lineages into diploid genomes following a WGD event. The process is thought to involve genome downsizing, subgenome-specific fractionation, and modulation of gene expression ${ }^{12}$. A key feature of genome fractionation during PPD is that one of the parental subgenomes generally retains significantly more genes as compared with the other subgenome, especially in the case of dosage-sensitive genes ${ }^{55}$. Such genes are in- 
volved in macromolecular complexes, transcription regulation and responses to environmental stimuli ${ }^{56}$. The determination of genome dominance is suspected to be linked to differences in the density of transposable elements, methylation and siRNA expression ${ }^{55}$. For instance, the subgenome A of A. suecica shows decreased levels of CG methylation and transcriptional upregulation at loci required for proper chromatid alignment during meiosis, possibly as a mechanism to promote reproductive stability ${ }^{18}$. Example loci are homologs of STRUCTURAL MAINTENANCE OF CHROMOSOMES 3/TITAN 7 (SMC3/TTN7; At2g27170), SMC1/TTN8 (At3g54670), SMC6B/MIM (At5g61460) and PDS5B (At1g77600).

At the cytological level, PPD may manifest in orchid hybrids as chromosomal rearrangements such as centric fissions, inversions and Robertsonian translocations between homologous and non-homologous chromosomes that lead to speciation and diversification. Or if expressed alternatively, PPD may transform a polyploid genome into a quasidiploid one with a lower base chromosome number (x) (e.g., descending disploidy) that reverts the number of linkage groups to the same number as the diploid ancestors ${ }^{12}$. Inversion loops and translocation junctions have been reported at pachytene in Doritaenopsis Fuchsia Princess 'KHM648' $(2 \mathrm{x}=38){ }^{57}$. However, chromosomal bridges have been observed at anaphase I in chromosomes of Dtps. Sweet Strawberry 'Wei' $(4 \mathrm{x}=76)$ and Dtps. Ben Yu Star 'Red Dragon' $(4 x=76){ }^{21}$, both suggesting the existence of PPD in commercial hybrids.

Although not entirely obvious, commercial hybrids may offer the opportunity to study orchid PPD in real time and in a controlled setting to facilitate understanding the molecular mechanisms that are believed to mediate PPD and genome fractionation, such as chromatin accessibility and histone modifications 55 .

The experimental hurdle is that the Orchidaceae family comprises more than 28000 species and 736 genera and that the patterns of karyotype evolution are not well understood ${ }^{12}$. What is clear is that the sequenced orchid genomes that are currently available (Phalaenopsis equestris, Dendrobium catenatum, Dendrobium officinale and Apostaceae shenzhenica) appear to have high chromosome numbers $(2 x=38$ and $2 x=68)$, which suggests paleo-polyploid origins ${ }^{12,58}$. Also, a huge disparity in orchid chromosome numbers, ranging from 12 in Erycina pusilla to 240 in Epidendrum cinnabarinum, indicates that many WGD events followed by diploidization may have taken place during evolution across different clades $12,59,60$.

In contrast, by comparing the karyotypes of species in Phalaenopsis versus interspecific hybrids, one may deduce, in a short time, a few trends for PPD. For instance 1) during the selection of sexually fertile progenies in harlequin and novelty cultivars $(P$. Chian Xen Magpie, $P$. Chian Xen Piano 'CX339'), there is a strong fractionation bias against large chromosomes from sections Polychilos, Esmeraldae and Parishianae; 2) in specific triploids such as P. Golden Sands 'Canary', P. Taipei Gold 'STM', P. Queen Beer 'Mantefon', P. Joy Spring Canary 'Taipei', P. Sogo Relax 'Sogo F-987' and P. Liu's Berry 'SW', irregular pairing of chromosomes is common, presumably due to chromosomal rearrangements; and 3 ) the production of unreduced gametes has certainly led to the formation of valuable tetraploids such as P. Taipei Gold 'Gold Star' and P. Paifang's Queen 'Brother' 61. Finally, the implementation of genomic in situ hybridization may facilitate the identification of parental genomes for the introgression of key horticultural traits, and the identification of alleles for OSD1 and TAM might accelerate the development of new elite polyploids ${ }^{6}$.

\section{Induction of polyploidy on meiocytes}

A novel polyploid individual may form via different pathways, and depending on the pathway and the level of heterozygosity, a newly formed polyploid will perform better, as evidenced by gains in growth, fertility, and horticultural quality 7,62. This is important because horticulturally speaking, the current understanding of inter- and intrageneric polyploidization in Phalaenopsis, Epidendrum, Lycaste and Cymbidium has been obtained from somatic chromosome doubling with colchicine in solid and liquid medium 
$(0.01-0.005 \%)^{47}$ or oryzalin in liquid medium up to $57 \mu \mathrm{M}^{7}$. However, this path does not reproduce what usually happens in nature because mitotic non-disjunction of sister-chromatids in meristem tissues, zygotes or embryos is rare and unfortunately restricts the number of alleles fixed per locus in auto- and allotetraploids ${ }^{62}$. In contrast, meiotic chromosome doubling is known to result in larger genetic variability, fitness and heterozygosity than somatic (mitotic) doubling 63

In cultured Cymbidium, unreduced gametes form at a rate of $0.15 \%$ in the cultivar 'Xiaoxiang' to $4.03 \%$ in cultivar ' $47-17$ ', and the formation is believed to be the highest in interspecific hybrids ${ }^{2}$. However, in Begonia, the formation of $2 \mathrm{n}$ gametes can be boosted by treating pollen mother cells with trifluralin (10, 100 and $1000 \mu \mathrm{M}$ in 5\% DMSO for 24 h) and nitrous oxide $\left(\mathrm{N}_{2} \mathrm{O}\right)$ at 6 bar $(600 \mathrm{kPa})$ for $48 \mathrm{~h}{ }^{63}$. Also, in Populus canescens, the injection of colchicine $(0.5 \% \mathrm{v} / \mathrm{v})$ during pachytene leads to unreduced gamete production at an astonishing rate of $30 \%$, with the germination rate not significantly affected (22\% vs. $23 \%$ in natural unreduced gametes).

Work in Caenorhabditis elegans suggests that during meiosis, colchicine affects the formation of the SC and disrupts the structure of the nuclear envelope ${ }^{64}$. Colchicine is a dinitro-sulfonamide herbicide and worm killer that binds selectively to $\alpha$-tubulin and inhibits polymerization of microtubules. However, it is also a hydrophobic compound that may rupture membranes similar to detergents ${ }^{64}$. Oryzalin is a dinitro-aniline herbicide that has higher affinity to plant tubulins ${ }^{7}$. Trifluralin and $\mathrm{N}_{2} \mathrm{O}$ are believed to disrupt meiotic cytokinesis ${ }^{63}$. Trifluralin is a plant-specific dinitro-toluidine herbicide that also targets tubulin ${ }^{65}$. Trifluralin and colchicine may be applied directly to meiotic flower buds of $P$. Sogo Yukidian 'V3' (see Figures $1 \mathrm{~A}$ and $1 \mathrm{~B}$ ) in lanolin paste $(0.09-0.13 \%$ and $0.05-$ $0.1 \%$ ) to induce the formation of $2 \mathrm{n}$ gametes ${ }^{48}$.

\section{Conclusions}

Meiotic polyploidization is a key element for successful plant breeding, and it may allow for the development of new and exciting orchid hybrids, as in Phalaenopsis. However, as an evolutionary process, it is complex and may involve genome fractionation, dysploidy, and homoeologous recombination. Thus, its study in orchids may also allow for a better understanding of the molecular forces that shape selection and survival in the wild.

\section{Figures and Legends}

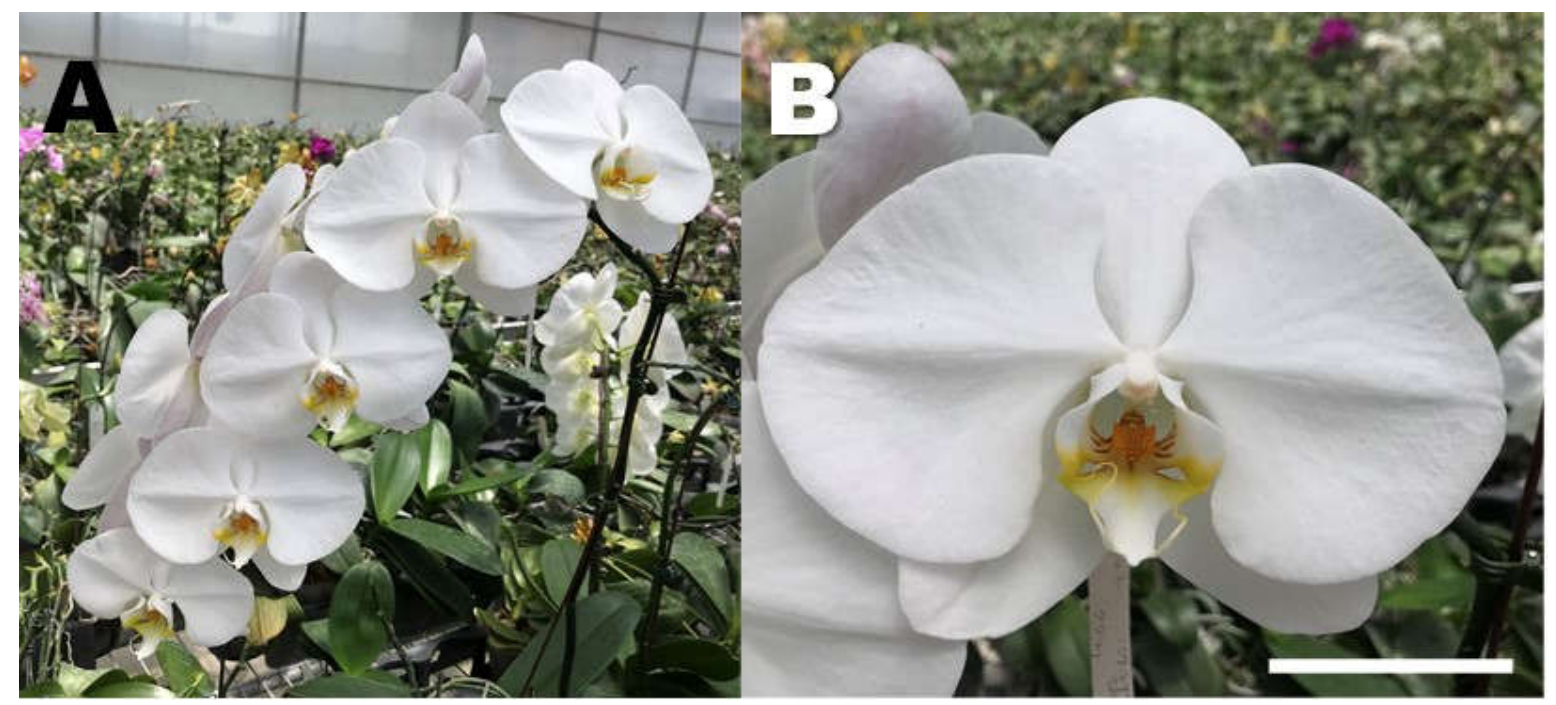

Figure 1. Flower spike (A) and individual flower (B) in elite tetraploid hybrid Phalaenopsis Sogo Yukidian 'V3' $(2 \mathrm{n}=4 \mathrm{x}=76)$, the standard white hybrid most sold in Taiwan. This extremely stable meiotic hybrid was derived from Phalaenopsis Doris, an old interspecific hybrid synthesized from crossing Phalaenopsis amabilis, Phalaenopsis rimestadiana and Phalaenopsis aphrodite. The spikes carry 
multiple flowers all evenly spaced, and the flowers themselves are symmetrical, large, flat, and long lived. Scale bar: $2.5 \mathrm{~cm}$. Photos taken by F.C. Chen in Pingtung County, 2022.

Acknowledgments: This work was supported by grants C0244 and C2060 from Vicerrectoría de Investigación, University of Costa Rica. The article processing fee was also kindly covered by the Vicerrectoría de Investigación, University of Costa Rica. Special thanks to Laura Smales at BioMedEditing (Toronto, Canada) for English editing.

Author Contributions: PBV.; writing - original draft preparation, FCC.; writing - review and editing.

Conflicts of Interest: The authors declare no conflict of interest.

\section{References}

1. Chen, W. H.; Kao, Y. L.; Tang, C. Y.; Tsai, C. C.; Lin, T. Y. Estimating Nuclear DNA Content within 50 Species of the Genus Phalaenopsis Blume (Orchidaceae). Scientia Horticulturae 2013, 161, 70-75. https://doi.org/10.1016/j.scienta.2013.06.045.

2. Zeng, R. Z.; Zhu, J.; Xu, S. Y.; Du, G. H.; Guo, H. R.; Chen, J.; Zhang, Z. S.; Xie, L. Unreduced Male Gamete Formation in Cymbidium and Its Use for Developing Sexual Polyploid Cultivars. Frontiers in Plant Science 2020, $11,558$. https://doi.org/10.3389/fpls.2020.00558.

3. Kamemoto, H.; D'Amore, T.; Kuenhle, A. R. Breeding Dendrobium Orchids in Hawaii, 1st ed.; University of Hawai'i Press: Honolulu, 1999.

4. Lee, Y.-I.; Chung, M. C. Karyomorphological Observation on Some Paphiopedilum Hybrids. Acta Horticulturae 2010, 878, 99106.

5. Hu, C. J.; Lee, N.; Lee, Y. I. Meiotic Defects and Premature Tapetal Degeneration Are Involved in the Low Fertility of Oncidesa Gower Ramsey, an Important Cut-Flower Orchid. HortScience 2018, 53 (9), 1283-1287. https://doi.org/10.21273/HORTSCI1301118.

6. Vo, T. C.; Lee, J.; Son, B. G.; Kim, C. K.; Kim, H. Y.; Lim, K. B. Phenotypic Correlation Analysis of Phalaenopsis Reciprocal F1 Hybrids Using SPSS and Principal Component Analysis (PCA). In Acta Horticulturae; International Society for Horticultural Science, 2019; Vol. 1262, pp 213-218. https://doi.org/10.17660/ActaHortic.2019.1262.28.

7. Miguel, T. P.; Leonhardt, K. W. In Vitro Polyploid Induction of Orchids Using Oryzalin. Scientia Horticulturae 2011, 130 (1), $314-$ 319. https://doi.org/10.1016/j.scienta.2011.07.002.

8. Teoh, S. B.; Ong, E. C. Differential Meiotic Behaviour in Hybrids Clones of Aranda "Christine" (Orchidaceae). Euphytica 1983, 32, 799-806.

9. Tanaka, R.; Kamemoto, H. Meiotic Chromosome Behavior in Diploid and Polyploid Vanda Orchid Hybrids. Cytologia 1960, 25, 405-418.

10. van de Peer, Y.; Mizrachi, E.; Marchal, K. The Evolutionary Significance of Polyploidy. Nature Reviews Genetics 2017, 18 (7), 411424. https://doi.org/10.1038/nrg.2017.26.

11. van de Peer, Y.; Ashman, T. L.; Soltis, P. S.; Soltis, D. E. Polyploidy: An Evolutionary and Ecological Force in Stressful Times. The Plant Cell 2021, 33 (1), 11-26. https://doi.org/10.1093/plcell/koaa015.

12. Mandáková, T.; Lysak, M. A. Post-Polyploid Diploidization and Diversification through Dysploid Changes. Current Opinion in Plant Biology 2018, 42, 55-65. https://doi.org/10.1016/j.pbi.2018.03.001.

13. Chen, Y. Y.; Hsiao, Y. Y.; Li, C. I.; Yeh, C. M.; Mitsuda, N.; Yang, H. X.; Chiu, C. C.; Chang, S. bin; Liu, Z. J.; Tsai, W. C. The Ancestral Duplicated DL/CRC Orthologs, PeDL1 and PeDL2, Function in Orchid Reproductive Organ Innovation. Journal of Experimental Botany 2021, 72 (15), 5442-5461. https://doi.org/10.1093/jxb/erab195.

14. Cai, J.; Liu, X.; Vanneste, K.; Proost, S.; Tsai, W.-C.; Liu, K.-W.; Chen, L.-J.; He, Y.; Xu, Q.; Bian, C.; Zheng, Z.; Sun, F.; Liu, W.; Hsiao, Y.-Y.; Pan, Z.-J.; Hsu, C.-C.; Yang, Y.-P.; Hsu, Y.-C.; Chuang, Y.-C.; Dievart, A.; Jean-Francois Dufayard, X. X.; Wang, J.Y.; Wang, J.; Xiao, X.-J.; Zhao, X.-M.; Du, R.; Zhang, G.-Q.; Wang, M.; Su, Y.-Y.; Xie, G.-C.; Liu, G.-H.; Li, L.-Q.; Huang, L.-Q.; Luo, Y.-B.; Chen, H.-H.; van de Peer, Y.; Liu, Z.-J. The Genome Sequence of the Orchid Phalaenopsis equestris. Nature Genetics 2015, 47, 65-72. https://doi.org/10.1038/ng.3149.

15. Gross, K.; Schiestl, F. P. Are Tetraploids More Successful? Floral Signals, Reproductive Success and Floral Isolation in MixedPloidy Populations of a Terrestrial Orchid. Annals of Botany 2015, 115 (2), 263-273. https://doi.org/10.1093/aob/mcu244.

16. Sharma, S. K.; Yamamoto, M.; Mukai, Y. Delineation of Methylation and Histone Modification: The Epigenetic Regulatory Marks Show Slightly Altered Distribution with the Elevation in Ploidy Level in the Orchid Dendrobium nobile. Nucleus (India) 2018, 61 (3), 183-193. https://doi.org/10.1007/s13237-018-0231-1.

17. Osabe, K.; Kawanabe, T.; Sasaki, T.; Ishikawa, R.; Okazaki, K.; Dennis, E. S.; Kazama, T.; Fujimoto, R. Multiple Mechanisms and Challenges for the Application of Allopolyploidy in Plants. International Journal of Molecular Sciences 2012, 13 (7), 8696-8721. https://doi.org/10.3390/ijms13078696.

18. Jiang, X.; Song, Q.; Ye, W.; Chen, Z. J. Concerted Genomic and Epigenomic Changes Accompany Stabilization of Arabidopsis Allopolyploids. Nature Ecology \& Evolution 2021, 5, 1382-1393. https://doi.org/10.1038/s41559-021-01523-y. 
19. Blasio, F.; Prieto, P.; Pradillo, M.; Naranjo, T. Genomic and Meiotic Changes Accompanying Polyploidization. Plants 2022, 11 (1), 125. https://doi.org/10.3390/plants11010125.

20. Chen, F. C.; Chin, S. W.; Huang, J. Z. Novel Orchid Breeding to Meet Future Market Demands. In Acta Horticulturae; International Society for Horticultural Science, 2021; Vol. 1312, pp 1-7. https://doi.org/10.17660/ActaHortic.2021.1312.1.

21. Bolaños-Villegas, P.; Chen, F. C. Cytological Identification of Chromosomal Rearrangements in Doritaenopsis and Phalaenopsis. Journal of International Cooperation 2007, 2 (1), 1-11. https://doi.org/10.13140/RG.2.1.1641.8007.

22. Cui, L.; Sun, Y.; Xiao, K.; Wan, L.; Zhong, J.; Liu, Y.; Xie, Q.; Zhou, S. Analysis on the Abnormal Chromosomal Behaviour and the Partial Female Fertility of Allotriploid Lilium - 'Triumphator' (LLO) Is Not Exceptional to the Hypothesis of Lily Interploid Hybridizations. Scientia Horticulturae 2022, 293. https://doi.org/10.1016/j.scienta.2021.110746.

23. de Storme, N.; Copenhaver, G. P.; Geelen, D. Production of Diploid Male Gametes in Arabidopsis by Cold-Induced Destabilization of Postmeiotic Radial Microtubule Arrays. Plant Physiology 2012, $160 \quad$ (4), $1808-1826$. https://doi.org/10.1104/pp.112.208611.

24. Bretagnolle, F.; Thompson, J. D. Gametes with the Somatic Chromosome Number: Mechanisms of Their Formation and Role in the Evolution of Autopolyploid Plants. New Phytologist 1995, 129, 1-22.

25. Liu, B.; de Storme, N.; Geelen, D. Gibberellin Induces Diploid Pollen Formation by Interfering with Meiotic Cytokinesis. Plant Physiology 2017, 173 (1), 338-353. https://doi.org/10.1104/pp.16.00480.

26. Ansari, H. A.; Ellison, N. W.; Verry, I. M.; Williams, W. M. Asynapsis and Unreduced Gamete Formation in a Trifolium Interspecific Hybrid. BMC Plant Biology 2022, 22 (1), 14. https://doi.org/10.1186/s12870-021-03403-w.

27. Zamariola, L.; Tiang, C. L.; de Storme, N.; Pawlowski, W.; Geelen, D. Chromosome Segregation in Plant Meiosis. Frontiers in Plant Science 2014, 5, 1-19. https://doi.org/10.3389/fpls.2014.00279.

28. Yang, C.; Hamamura, Y.; Sofroni, K.; Böwer, F.; Stolze, S. C.; Nakagami, H.; Schnittger, A. SWITCH 1/DYAD Is a WINGS APART-LIKE Antagonist That Maintains Sister Chromatid Cohesion in Meiosis. Nature Communications $2019,10,1755$. https://doi.org/10.1038/s41467-019-09759-w.

29. Bolaños-Villegas, P. Chromosome Engineering in Tropical Cash Crops. Agronomy 2020, 10, 122. https://doi.org/10.3390/agronomy10010123.

30. de Storme, N.; Copenhaver, G. P.; Geelen, D. Production of Diploid Male Gametes in Arabidopsis by Cold-Induced Destabilization of Postmeiotic Radial Microtubule Arrays. Plant Physiology 2012, 160, 1908-1826. https://doi.org/10.1104/pp.112.208611.

31. Kuo, P.; da Ines, O.; Lambing, C. Rewiring Meiosis for Crop Improvement. Frontiers in Plant Science $2021,12$. https://doi.org/10.3389/fpls.2021.708948.

32. Navarro, E. J.; Marshall, W. F.; Fung, J. C. Modeling Cell Biological Features of Meiotic Chromosome Pairing. bioRxiv 2022, 119. https://doi.org/10.1101/2022.01.06.475288.

33. Shahid, S. The Rules of Attachment: Rec8 Cohesin Connects Chromatin Architecture and Recombination Machinery in Meiosis. Plant Cell 2020, 32 (4), 808-829. https://doi.org/10.1105/tpc.20.00094.

34. Bai, X.; Peirson, B. N.; Dong, F.; Xue, C.; Makaroff, C. A. Isolation and Characterization of SYN1, a RAD21-like Gene Essential for Meiosis in Arabidopsis. The Plant Cell 1999, 11 (3), 417-430. https://doi.org/10.1105/tpc.11.3.417.

35. d'Erfurth, I.; Cromer, L.; Jolivet, S.; Girard, C.; Horlow, C.; Sun, Y.; To, J. P. C.; Berchowitz, L. E.; Copenhaver, G. P.; Mercier, R. The CYCLIN-A CYCA1;2/TAM Is Required for the Meiosis I to Meiosis II Transition and Cooperates with OSD1 for the Prophase to First Meiotic Division Transition. PLoS Genetics 2010, 6 (6), e1000989.

36. Crismani, W.; Girard, C.; Mercier, R. Tinkering with Meiosis. Journal of Experimental Botany 2013, 64 (1), 55-65.

37. Khanday, I.; Skinner, D.; Yang, B.; Mercier, R.; Sundaresan, V. A Male-Expressed Rice Embryogenic Trigger Redirected for Asexual Propagation through Seeds. Nature 2019, 565, 91-95. https://doi.org/10.1038/s41586-018-0785-8.

38. Tong, C. G.; Wu, F. H.; Yuan, Y. H.; Chen, Y. R.; Lin, C. S. High-Efficiency CRISPR/Cas-Based Editing of Phalaenopsis Orchid MADS Genes. Plant Biotechnology Journal 2020, 18 (4), 889-891. https://doi.org/10.1111/pbi.13264.

39. Bulankova, P.; Akimcheva, S.; Fellner, N.; Riha, K. Identification of Arabidopsis Meiotic Cyclins Reveals Functional Diversification among Plant Cyclin Genes. PLoS Genetics 2013, 9 (5), e1003508.

40. Lei, X.; Ning, Y.; Eid Elesawi, I.; Yang, K.; Chen, C.; Wang, C.; Liu, B. Heat Stress Interferes with Chromosome Segregation and Cytokinesis during Male Meiosis in Arabidopsis thaliana. Plant Signaling and Behavior 2020, 15 (5). https://doi.org/10.1080/15592324.2020.1746985.

41. Wang, Z.; Wan, Y.; Meng, X.; Zhang, X.; Yao, M.; Miu, W.; Zhu, D.; Yuan, D.; Lu, K.; Li, J.; Qu, C.; Liang, Y. Genome-Wide Identification and Analysis of Mkk and Mapk Gene Families in Brassica Species and Response to Stress in Brassica napus. International Journal of Molecular Sciences 2021, 22 (2), 1-21. https://doi.org/10.3390/ijms22020544.

42. Yang, C.; Spielman, M.; Coles, J. P.; Li, Y.; Ghelani, S.; Bourdon, V.; Brown, R.; Lemmon, B.; Scott, R.; Dickinson, H. TETRASPORE Encodes a Kinesin Required for Male Meiotic Cytokinesis in Arabidopsis. The Plant Journal 2003, 34, $229-240$.

43. Ning, Y.; Liu, Q.; Wang, C.; Qin, E.; Wu, Z.; Wang, M.; Eid Elesawi, I.; Chen, C.; Liu, H.; Qin, R.; Liu, B. Heat Stress Interferes with Formation of Double-Strand Breaks and Homology Synapsis in Arabidopsis thaliana. bioRxiv 2020, 2020.10.02.324269. https://doi.org/https://doi.org/10.1101/2020.10.02.324269. 
44. France, M. G.; Enderle, J.; Röhrig, S.; Puchta, H.; Franklin, F. C. H.; Higgins, J. D. ZYP1 Is Required for Obligate Cross-over Formation and Cross-over Interference in Arabidopsis. Proceedings of the National Academy of Sciences 2021, 118 (14). https://doi.org/10.1073/PNAS.2021671118.

45. Capilla-Pérez, L.; Durand, S.; Hurel, A.; Lian, Q.; Chambon, A.; Taochy, C.; Solier, V.; Grelon, M.; Mercier, R.; Institut, B.; Bourgin, J.-P. The Synaptonemal Complex Imposes Crossover Interference and Heterochiasmy in Arabidopsis. Proceedings of the National Academy of Sciences 2021, 118 (12), 1-11. https://doi.org/10.1073/pnas.2023613118/-/DCSupplemental.

46. de Jaeger-Braet, J.; Krause, L.; Buchholz, A.; Schnittger, A. Heat Stress Reveals a Specialized Variant of the Pachytene Checkpoint in Meiosis of Arabidopsis thaliana. The Plant Cell 2022, 34 (1), 433-454. https://doi.org/10.1093/plcell/koab257.

47. Aoyama, M. Chromosome Research for Orchid Breeding. Acta Horticulturae 2010, 878, 125-132.

48. Hsu, S.-T.; Chuang, H.-T.; Shen, T.-M. Breeding Barriers in Red Phalaenopsis Orchids. Acta Horticulturae 2010, 878, 145-152.

49. Pelé, A.; Falque, M.; Trotoux, G.; Eber, F.; Nègre, S.; Gilet, M.; Huteau, V.; Lodé, M.; Jousseaume, T.; Dechaumet, S.; Morice, J.; Poncet, C.; Coriton, O.; Martin, O. C.; Rousseau-Gueutin, M.; Chèvre, A. M. Amplifying Recombination Genome-Wide and Reshaping Crossover Landscapes in Brassicas. PLoS Genetics 2017, 13 (5). https://doi.org/10.1371/journal.pgen.1006794.

50. Higgins, E. E.; Howell, E. C.; Armstrong, S. J.; Parkin, I. A. P. A Major Quantitative Trait Locus on Chromosome A9, BnaPh1, Controls Homoeologous Recombination in Brassica napus. New Phytologist 2021, $229,3281-3293$. https://doi.org/10.1111/nph.16986.

51. Enderle, J.; Dorn, A.; Beying, N.; Trapp, O.; Puchta, H. The Protease WSS1A, the Endonuclease MUS81, and the Phosphodiesterase TDP1 Are Involved in Independent Pathways of DNA-Protein Crosslink Repair in Plants. The Plant Cell 2019, 31, 775-790. https://doi.org/10.1105/tpc.18.00824.

52. Aklilu, B. B.; Soderquist, R. S.; Culligan, K. M. Genetic Analysis of the Replication Protein A Large Subunit Family in Arabidopsis Reveals Unique and Overlapping Roles in DNA Repair, Meiosis and DNA Replication. Nucleic Acids Research 2014, 42 (5), 31043118. https://doi.org/10.1093/nar/gkt1292.

53. Gonzalo, A.; Lucas, M.-O.; Charpentier, C.; Sandmann, G.; Lloyd, A.; Jenczewski, E. Reducing MSH4 Copy Number Prevents Meiotic Crossovers between Non-Homologous Chromosomes in Brassica napus. Nature Communications 2019, $10,2354$. https://doi.org/10.1038/s41467-019-10010-9.

54. Teoh, S. B. Complement Fractionation in Natural Diploid Orchid Species. Theoretical and Applied Genetics 1982, $61,91-95$. https://doi.org/https://doi.org/10.1007/BF00261517.

55. Edger, P. P.; Bird, K. A.; VanBuren, R.; Puzey, J. R. Tansley Insight: The Causes and Consequences of Subgenome Dominance in Hybrids and Recent Polyploids. New Phytologist 2018, 220, 87-93. https://doi.org/10.1111/nph.15256.

56. Cheng, F.; Wu, J.; Cai, X.; Liang, J.; Freeling, M.; Wang, X. Gene Retention, Fractionation and Subgenome Differences in Polyploid Plants. Nature Plants 2018, 4, 258-268. https://doi.org/10.1038/s41477-018-0136-7.

57. Bolaños-Villegas, P.; Chin, S.-W.; Chen, F.-C. Meiotic Chromosome Behavior and Capsule Setting in Doritaenopsis Hybrids. Journal of the American Society for Horticultural Science 2008, 133 (1), 107-116.

58. Tsai, W. C.; Dievart, A.; Hsu, C. C.; Hsiao, Y. Y.; Chiou, S. Y.; Huang, H.; Chen, H. H. Post Genomics Era for Orchid Research. Botanical Studies 2017, 58 (61), 1-22. https://doi.org/10.1186/s40529-017-0213-7.

59. Felix, L. P.; Guerra, M. Chromosome Analysis in Psygmorchis pusilla (L.) Dodson \& Dressier: The Smallest Chromosome Number Known in Orchidaceae. Caryologia 1999, 52 (3-4), 165-168. https://doi.org/10.1080/00087114.1998.10589169.

60. Moraes, A. P.; Koehler, S.; Cabral, J. S.; Gomes, S. S. L.; Viccini, L. F.; Barros, F.; Felix, L. P.; Guerra, M.; Forni-Martins, E. R. Karyotype Diversity and Genome Size Variation in Neotropical Maxillariinae Orchids. Plant Biology 2017, 19 (2), $298-308$. https://doi.org/10.1111/plb.12527.

61. Lee, Y. I.; Tseng, Y. F.; Lee, Y. C.; Chung, M. C. Chromosome Constitution and Nuclear DNA Content of Phalaenopsis Hybrids. Scientia Horticulturae 2020, 262. https://doi.org/10.1016/j.scienta.2019.109089.

62. Naranjo, T.; Yang, M.; Carmen Martin, A.; Pelé, A.; Rousseau-Gueutin, M.; Chèvre, A.-M. Speciation Success of Polyploid Plants Closely Relates to the Regulation of Meiotic Recombination. Frontiers in Plant Science 2018 , 9, 907. https://doi.org/10.3389/fpls.2018.00907.

63. Dewitte, A.; Eeckhaut, T.; Huylenbroeck, J. van; van Bockstaele, E. Induction of $2 \mathrm{n}$ Pollen Formation in Begonia by Trifluralin and $\mathrm{N}_{2} \mathrm{O}$ Treatments. Euphytica 2010, 171, 283-293. https://doi.org/10.1007/s10681-009-0060-z.

64. Goldstein, P. Exposure to the Anthelmintic Dinitroaniline Oryzalin Causes Changes in Meiotic Prophase Morphology and Loss of Synaptonemal Complexes in the Nematode Caenorhabditis elegans. Experimental Results 2021, 2, e38. https://doi.org/10.1017/exp.2021.19.

65. Zhao, J.; Simmonds, D. H. Application of Trifluralin to Embryogenic Microspore Cultures to Generate Doubled Haploid Plants in Brassica napus. Physiologia Plantarum 1995, 95 (2), 304-309. https://doi.org/10.1111/j.1399-3054.1995.tb00842.x. 